\title{
The Photopigment Melanopsin Is Exclusively Present in Pituitary Adenylate Cyclase-Activating Polypeptide-Containing Retinal Ganglion Cells of the Retinohypothalamic Tract
}

\author{
Jens Hannibal, Peter Hindersson, Sanne M. Knudsen, Birgitte Georg, and Jan Fahrenkrug \\ Department of Clinical Biochemistry, Bispebjerg Hospital, University of Copenhagen, DK-2400 Copenhagen, Denmark
}

\begin{abstract}
Mammalian circadian rhythms generated in the hypothalamic suprachiasmatic nuclei are entrained to the environmental light/ dark cycle via a monosynaptic pathway, the retinohypothalamic tract $(\mathrm{RHT})$. We have shown previously that retinal ganglion cells containing pituitary adenylate cyclase-activating polypeptide (PACAP) constitute the RHT. Light activates the RHT via unknown photoreceptors different from the classical photoreceptors located in the outer retina. Two types of photopigments, melanopsin and the cryptochromes (CRY1 and CRY2), both of which are located in the inner retina, have been suggested as "circadian photopigments." In the present study, we cloned rat melanopsin photopigment cDNA and produced a specific melanopsin antibody. Using in situ hybridization histochemistry combined with immunohistochemistry, we demon-
\end{abstract}

strate that the distribution of melanopsin was identical to that of the PACAP-containing retinal ganglion cells. Colocalization studies using the specific melanopsin antibody and/or cRNA probes in combination with PACAP immunostaining revealed that melanopsin was found exclusively in the PACAPcontaining retinal ganglion cells located at the surface of somata and dendrites. These data, in conjunction with published action spectra analyses and work in retinally degenerated ( $r d /$ $\mathrm{rd} / \mathrm{cl}$ ) mutant mice, suggest that melanopsin is a circadian photopigment located in retinal ganglion cells projecting to the biological clock.

Key words: colocalization; suprachiasmatic nucleus; circadian rhythm; rat; immunohistochemistry; melanopsin antibodies
Mammalian circadian rhythms of behavior and physiology are generated by the principal pacemaker located in the suprachiasmatic nucleus (SCN) of the hypothalamus (Klein et al., 1991). Internal circadian time is synchronized (entrained) by lightinduced resetting (photoentrainment) mechanisms via a monosynaptic pathway originating from a subset of retinal ganglion cells, the retinohypothalamic tract (RHT) (Moore and Lenn, 1972; Johnson et al., 1988; Levine et al., 1991; Moore et al., 1995). The retinal ganglion cells constituting the RHT contain the neuropeptide pituitary adenylate cyclase-activating polypeptide (PACAP) and glutamate (Hannibal et al., 2000, 2001a). Both neurotransmitters are thought to play a role in light entrainment of the clock, as indicated by phase-shifting capabilities on the endogenous rhythm via regulation of clock gene expression in the SCN (Ding et al., 1994; Hannibal et al., 1997, 2001b; von Gall et al., 1998; Chen et al., 1999; Harrington et al., 1999; Kopp et al., 1999; Mintz et al., 1999; Nielsen et al., 2001). Using c-fos immunoreactivity as a marker for neuronal activation, we have shown recently that PACAP-immunoreactive ganglion cells were activated by light during subjective day and at time points during the night, when light is able to phase shift the endogenous rhythm (Hannibal et al., 2001a). The photopigment involved in light activation of the RHT and its cellular localization in the retina

Received June 21, 2001; revised Sept. 28, 2001; accepted Oct. 1, 2001.

This study was supported by The Danish Biotechnology Center for Cellular Communication and The Danish Neuroscience Programme. J.H. received postdoctoral funding from Danish Medical Research Council Grant 0001716. The skillful technical assistance of Lea Larsen, Juliano Olsen, and Anita Hansen is gratefully acknowledged.

Correspondence should be addressed to Dr. Jens Hannibal, Department of Clinical Biochemistry, Bispebjerg Hospital, Bispebjerg Bakke 23, DK-2400 Copenhagen NV, Denmark. E-mail: J.Hannibal@inet.uni2.dk.

Copyright (ㄷ) 2001 Society for Neuroscience $0270-6474 / 01 / 210001-07 \$ 15.00 / 0$ are unknown. Previous studies in retinally degenerated mutant mice lacking rods $(r d / r d)$ (Foster et al., 1991) and both rods and cones $(\mathrm{rdta} / \mathrm{cl})$ (Freedman et al., 1999) have demonstrated that the classical opsin-based photoreceptor cells, rods and cones, are dispensable for the circadian light response (for review, see von Schantz et al., 2000). Similarly, many blind persons with no conscious perception of light exhibit normal photic entrainment of the circadian rhythm (Czeisler et al., 1995). The cryptochromes CRY1 and CRY2 have been suggested as circadian photopigments (Miyamoto and Sancar, 1999). However, knock-out mice lacking one or both of the $C R Y$ s adjust their behavior in response to the light/dark photoperiod similar to wild-type mice, indicating that these molecules are not necessary for photic signaling to the brain (van der Horst et al., 1999; Vitaterna et al., 1999). Recently, a new opsin named melanopsin was cloned (Provencio et al., 2000). Melanopsin belongs to one of four opsins expressed outside the photoreceptor layer of the retina; it is solely expressed in the inner mouse retina located in a small population of retinal ganglion cells and some displaced amacrine and displaced ganglion cells.

This article is published in The Journal of Neuroscience, Rapid Communications Section, which publishes brief, peerreviewed papers online, not in print. Rapid Communications are posted online approximately one month earlier than they would appear if printed. They are listed in the Table of Contents of the next open issue of JNeurosci. Cite this article as: JNeurosci, 2002, 22:RC191 (1-7). The publication date is the date of posting online at www.jneurosci.org.

http://www.jneurosci.org/cgi/content/full/5919 
Using PACAP as a marker for the RHT-projecting retinal ganglion cells and using in situ hybridization combined with immunohistochemistry, we show here that the distribution of melanopsin mRNA and protein in the rat retina is identical to that of the PACAP-containing retinal ganglion cells, and that melanopsin is exclusively present in PACAP-immunoreactive cells.

\section{MATERIALS AND METHODS}

\section{Animals and tissue preparation}

Male Wistar rats $(180-220 \mathrm{gm} ; n=20)$ housed under standard laboratory conditions in a $12 \mathrm{hr}$ light/dark cycle with access to food and water ad libitum were used in the study. [Light was turned on at zeitgeber 0 (ZT0) and turned off at ZT12.] Experiments were performed according to the principles of laboratory animal care in Denmark (Publication No. 382; June 10,1987). Because initial experiments showed the highest level of both PACAP and melanopsin at subjective day, animals were killed between ZT0 and ZT8. Animals were decapitated and eyes were rapidly removed after marking the most medial point of the cornea with ink to allow orientation of the retina. After removal of the cornea and the anterior chamber, the vitreous body was gently removed. The retinas located in situ in the posterior chamber were fixed in Stefanini's fixative ( $2 \%$ paraformaldehyde and $0.2 \%$ picric acid in $0.1 \mathrm{M}$ sodium phosphate buffer, $\mathrm{pH} 7.2$ ) for $12-24 \mathrm{hr}$ at $4^{\circ} \mathrm{C}$, removed from the eyecup, transferred to cryoprotectant, and stored at $-20^{\circ} \mathrm{C}$ until they were processed for in situ hybridization and immunohistochemistry as whole mounts according to procedures described below. Eyeballs from additional animals were sectioned rather than processed as whole mounts. In these cases, sections (12 $\mu \mathrm{m} / \mathrm{section})$ were cut perpendicular to the long axis of the eyeball to allow a determination of the laminar localization of melanopsin and/or PACAP gene-expressing cells.

\section{Cloning of the rat melanopsin $c D N A$}

A 498 bp cDNA fragment of rat melanopsin was obtained from purified total RNA extracted from rat retinas by reverse transcriptase (RT)-PCR using the following primers: 5'-GTCCTGCTAGGCGTCTTGGCTTTAT-3' and 5'-GTACTTGGGGTGAGTGATGGCGTA-3' (SigmaGenosys Ltd., Cambridgeshire, UK). The product was cloned into the pcDNA3.1/V5/His-TOPO vector (Invitrogen, Groningen, The Netherlands) and sequenced.

The rat melanopsin cDNA fragment was localized in the coding region covering transmembrane 4 to transmembrane 7 . Comparison with the published mouse sequence (Provencio et al., 2000) revealed that the rat melanopsin has a deletion of an arginine corresponding to the $1016 \mathrm{bp}$ position in the mouse sequence.

\section{In situ hybridization histochemistry}

In vitro labeling of cRNA antisense and sense probes was performed as described previously using ${ }^{33}$ P-UTP (Hannibal et al., 1997). The cDNA templates were the above-mentioned melanopsin plasmid and a plasmid containing rat PACAP cDNA (Hannibal et al., 1999). In situ hybridization was performed using a previously published protocol with slight modifications (Hannibal et al., 1997). Briefly, after treatment in acetic anhydride, dehydration in $70 \%$ ethanol, and prehybridization $(2 \mathrm{hr})$, whole-mount retinas were hybridized with melanopsin and/or PACAP cRNA probes, fragmented by incubation in hydrolysis buffer for $50 \mathrm{~min}$ at $60^{\circ} \mathrm{C}$, and used at a concentration of $1 \times 10^{7} \mathrm{cpm} / \mathrm{ml}$. After hybridization, washing, RNase treatment, and a final washing, the radioactive labeled retinas were either immunostained for PACAP (see below) or placed on gelatin-coated slides, dried, emulsion dipped (Amersham, Copenhagen, Denmark), and exposed for 2-3 weeks before being developed. Hybridization was routinely performed in parallel using an antisense and a sense probe on retinas from the same animal; no signal was obtained using the sense probes.

\section{Determination of the density of melanopsin- and PACAP- expressing retinal ganglion cells}

Determination of the number of retinal ganglion cells containing melanopsin and PACAP mRNA was performed as described previously (Hannibal et al., 2001a). Briefly, retinas from the same animal hybridized with melanopsin and/or PACAP probes were examined in a $430 \times 340$ $\mu \mathrm{m}$ square and images were grabbed via a Leica (Cambridge, UK)
DC200 camera using Leica DC200 software. Images from the central part of the upper and lower half of each retina were analyzed (Fig. $1 D, E, G, H$ ) using Leica QWin (version 2.2) software. Grayscale thresholds of the image analysis system were established that identified specific melanopsin and/or PACAP mRNA-containing cells. Positive cells with signals above threshold from each section were then compiled and the number of ganglion cells containing melanopsin and PACAP mRNA was determined.

\section{Immunohistochemistry}

Melanopsin antibodies. A cDNA fragment encoding the C-terminal predicted cytoplasmatic part of mouse melanopsin was generated by RTPCR. The cDNA was made from total RNA prepared from mouse retinas using oligo(dT) primers and SuperScript (Life Technologies, Taastrup, Denmark). The PCR was done using the primers $5^{\prime}$-TCTTCATCTTCAGGGCCATC-3' and 5'-TTCTCTGCTGTAGGCCACATA-3' (Provencio et al., 2000) as well as platinum Taq polymerase (Life Technologies). The PCR fragment was cloned in pCRII-TOPO (Invitrogen). A clone containing 13 base mismatches was used as template for a second PCR using the primers $5^{\prime}$-CACCCCAAGTACAGGGTGGCCAT-3' and 5'-TTCTCTGCTGTAGGCCACATA-3'; the fragment from this second PCR was subcloned in the vector pCRT7/NT-TOPO (Invitrogen) as described by the manufacturer. The sequence contained an open reading frame that represents 160 amino acid residues (underlined) of the C-terminal cytoplasmatic part of mouse melanopsin (MRGSHHHHHHGMASMTGGQQMGRDLYDDDD-KDPTLHPK YRVAIAQHLPCLGV LLGVSGQRSHPSLSY RSTHRSTLSSQSSDLSWISGRKRQESLGSESEVGWTDTETTAAWG TAQQASGQSFCSQNLEDGELKASSSPQVQRSKTPK VPGPSSCRP MKGQGARPSSLRGDQKGRLAVCTGLSESPHSHTSQFPPCFPRG). The recombinant fusion protein was expressed in the host strain BL21(DE3)pLysS, extracted in Tris-equilibrated phenol, $\mathrm{pH}$ 8.0, and precipitated with ethanol. The protein pellet was solubilized in $6 \mathrm{~m}$ guanidinium chloride, $0.1 \mathrm{M}$ DTT, and $50 \mathrm{~mm}$ Tris, $\mathrm{pH}$ 8.0. The solubilized protein was passed over Sephadex G25 column equilibrated with $5 \mathrm{~mm}$ mercapthoethanol, $8 \mathrm{M}$ urea, $0.5 \mathrm{M} \mathrm{NaCl}$, and $50 \mathrm{~mm}$ Tris, $\mathrm{pH} 8.0$ (MUNT). Finally the His-tagged recombinant fusion protein was captured on a Ni-nitrilotriacetic acid Superflow column (Qiagen, Hilden, Germany); equilibrated with MUNT; washed in $0.5 \mathrm{~m} \mathrm{NaCl}$ and $50 \mathrm{~mm}$ Tris, $\mathrm{pH}$ 8.0; and eluted with 10 mM EDTA, $0.5 \mathrm{M} \mathrm{NaCl}$, and $50 \mathrm{~mm}$ Tris, $\mathrm{pH}$ 8.0. Four rabbits were immunized with $50 \mu \mathrm{g}$ of melanopsin fusion protein, dialyzed against $10 \mathrm{~mm}$ Tris and $0.15 \mathrm{M} \mathrm{NaCl}$. The immunization material was emulsified in an equal volume of complete Freund's adjuvant for the first immunization and incomplete Freund's adjuvant for the subsequent immunizations at $10 \mathrm{~d}$ intervals. Rabbit serum (code no. 41K9, diluted 1:1000) drawn by venipuncture 5 weeks after the second immunization reacted with purified recombinant protein (molecular mass of $28 \mathrm{kDa}$ ) in a Western blot performed as described previously (Hindersson et al., 1987). The Western blot antibody reactivity as well as immunostaining were removed by absorption of the anti-melanopsin antiserum with the immunization material.

$P A C A P$ antibody. A previously characterized mouse monoclonal antibody (code MabJHH1) directed against an epitope (amino acids 6-16) that recognizes both PACAP-38 and PACAP-27 was used for PACAP immunostaining (Hannibal et al., 1995). As a control, preabsorption of the antibody with PACAP-38 $(20 \mu \mathrm{g} / \mathrm{ml})$ was performed, which abolished all staining. Single- and double-antigen immunohistochemistry for visualization of melanopsin and PACAP was performed as described in detail previously (Fahrenkrug and Hannibal, 1998) using a mixture of biotinylated goat anti-mouse antiserum, Cy2-conjugated donkey antirabbit antiserum (Jackson ImmunoResearch, West Grove, PA), biotinylated tyramide (tyramide system amplification; DuPont NEN, Boston, MA) and streptavidin-conjugated Texas Red.

\section{Photomicrographs}

Images were obtained via a Leica DC200 camera using Leica DC200 software; for double immunohistochemistry, an Olympus IX70 confocal microscope equipped with Flouview v 2.1.39 (Olympus, Copenhagen, Denmark) was used. Image-editing software (Adobe Photoshop and Adobe Illustrator; Adobe Systems, San Jose, CA) was used to combine the obtained images into plates, and figures were printed on a Tektronix (Wilsonville, OR) Phaser 450 dye sublimation printer.

\section{RESULTS}

Using in situ hybridization and immunohistochemistry, melanopsin mRNA and protein were detected in a subset of retinal 

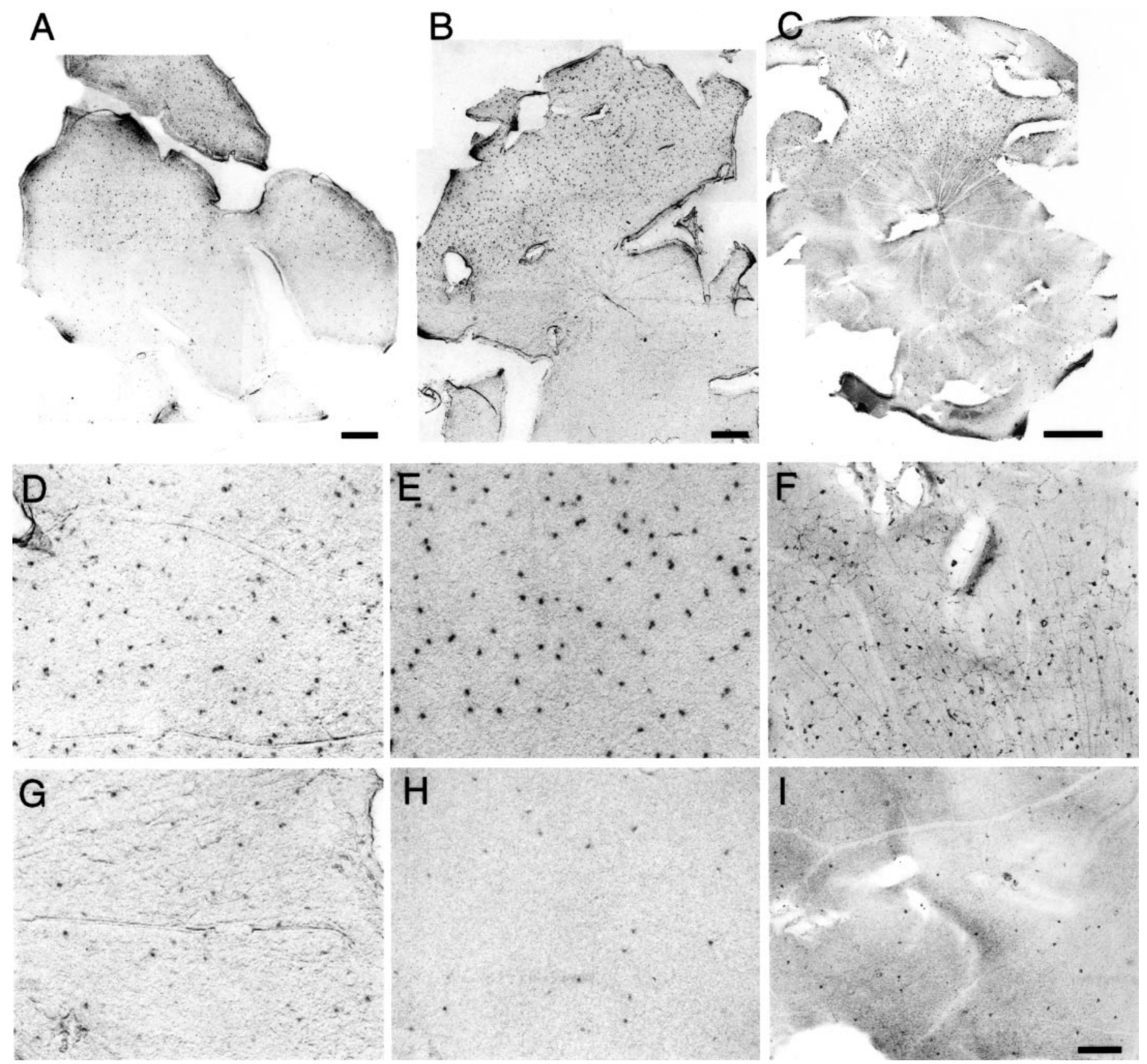

Figure 1. Melanopsin and PACAP expression in the rat retina. In situ hybridization histochemistry on whole-mount rat retinas using ${ }^{33} \mathrm{P}-\mathrm{UTP}-\mathrm{labeled}$ cRNA probes for melanopsin mRNA $(A, D, G)$, PACAP mRNA $(B, E, H)$, and PACAP immunoreactivity $(C, F, I)$ demonstrate an identical distribution pattern for melanopsin and PACAP located to a subset of retinal ganglion cells. Higher magnification clearly showed a fourfold to fivefold higher density of melanopsin- and PACAP-expressing retinal ganglion cells in the superior half of the retina $(D-F)$ compared with the inferior half $(G-I)$. Scale bars: $A-C, 1000 \mu \mathrm{m} ; D-I, 200 \mu \mathrm{m}$.

ganglion cells distributed throughout the retina and in a few seemingly displaced ganglion or displaced amacrine cells located between the ganglion cell layer and the inner nuclear cell layer (INL) (Figs. 1A,D, G, 2; also see Fig. 4). However, the distribution pattern was not uniform, because the density of ganglion cells containing melanopsin was in the range of $36-39$ cells $/ \mathrm{mm}^{2}$ in the superior half of the retina and $5-9$ cells $/ \mathrm{mm}^{2}$ in the lower half of the retina (Fig. 1D, G). The distribution of melanopsin-containing cells was identical to the distribution of retinal ganglion cells expressing PACAP mRNA. The density of the cells containing PACAP mRNA ranged from 31 to 37 cells $/ \mathrm{mm}^{2}$ in the superior half of the retina and from 5 to 8 cells $/ \mathrm{mm}^{2}$ in the lower half of the retina (Fig. 1E,H). Because an identical distribution of cells containing PACAP immunoreactivity was observed (Fig. $1 F, I$ ), we investigated whether melanopsin and PACAP were present in the same ganglion cells using either melanopsin mRNA probes for in situ hybridization histochemistry or the melanopsin antibody in combination with PACAP immunostaining. Melanopsin was demonstrated exclusively in the PACAP-containing retinal ganglion cells and in a few PACAP-expressing displaced ganglion or displaced amacrine cells (Figs. 2-4). The punctate melanopsin immunoreactivity was located at the surface of the ganglion cell 


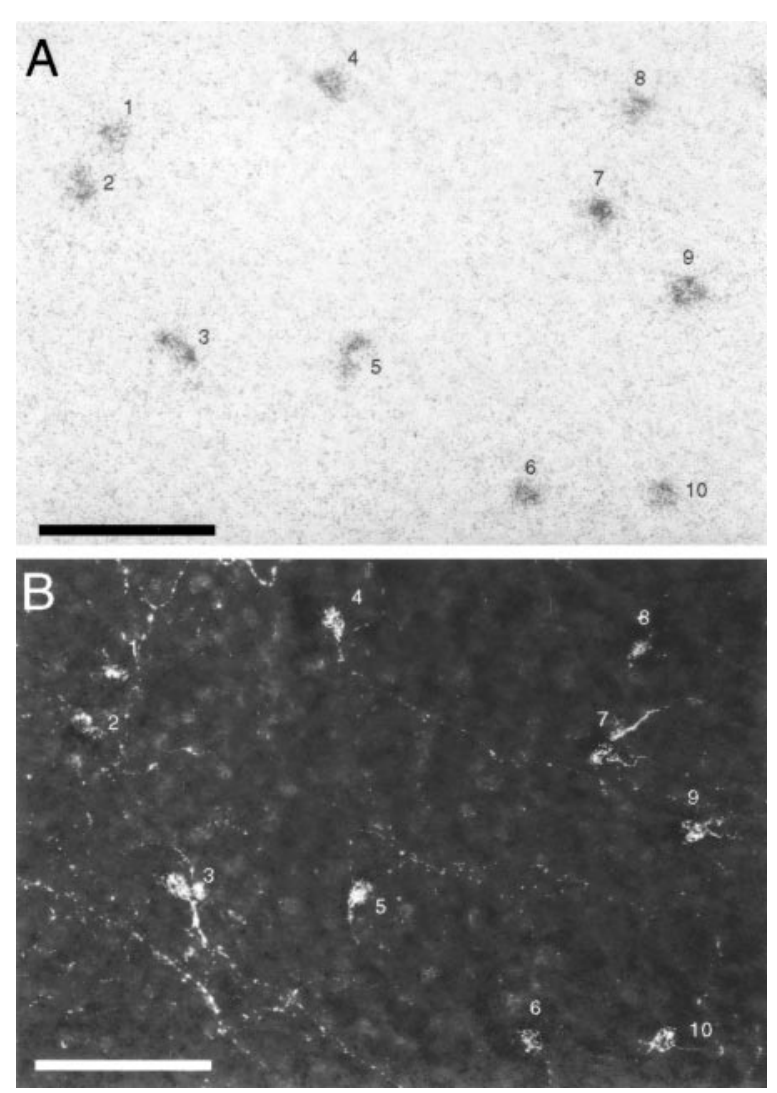

Figure 2. Melanopsin is colocalized with PACAP in retinal ganglion cells. A photomicrograph of melanopsin mRNA visualized by ${ }^{33} \mathrm{P}-\mathrm{UTP}$ labeled cRNA probes $(A)$ and PACAP immunostaining visualized by CY2 $(B)$ on the same whole-mount retina is shown. Individual retinal ganglion cells are numbered, and each number indicates the same cells in the two photomicrographs. Note that silver grains representing melanopsin mRNA are also present in the PACAP-containing retinal ganglion cells $(B)$. Scale bars, $100 \mu \mathrm{m}$.

at soma and the dendritic processes (Fig. 4). Melanopsin immunoreactivity could not be demonstrated in sections from the rat brain (data not shown).

\section{DISCUSSION}

In mammals, light entrainment of the clock is dependent on ocular light perception (Nelson and Zucker, 1981). However, mice lacking the classical rod and cone photoreceptors $(\mathrm{rdta} / \mathrm{cl}$ mice) are still able to entrain to a light/dark cycle (Freedman et al., 1999; Lucas et al., 1999), suggesting that unidentified photoreceptors located in other parts of the retina are responsible for light entrainment of the circadian rhythm (Lucas and Foster, 1999). Our finding that melanopsin is located exclusively in the PACAP-containing retinal ganglion cells constituting the RHT (Hannibal et al., 2001a) supports the existence of a "non-imageforming" visual pathway to the circadian system and makes melanopsin a candidate as a circadian photopigment. Additional support for this notion comes from an electrophysiological study on a flat-mount preparation of rat retina in vitro that demonstrated that SCN-projecting ganglion cells, in contrast to conventional ganglion cells, responded to light regardless of chemical blocking of synapses (Berson et al., 2001). Furthermore, the light response was not attributable to electrical coupling to rods and cones because the SCN projecting ganglion cells were depolarizing, not hyperpolarizing as the in rods and cones, suggesting that the phototransduction occurs within these retinal ganglion cells themselves. Another interesting observation of the present study was that the localization of melanopsin immunoreactivity was restricted to the membrane of the cell soma and to processes within the retina but not to processes in the optic nerve or in the brain. This localization increases the light-perceiving surface of the ganglion cells projecting to the SCN and may increase their sensitivity to light stimulation.

\section{The melanopsin photopigment is located in ganglion cells constituting the RHT}

As reported for melanopsin mRNA in mice (Provencio et al., 2000), we found that melanopsin (mRNA and protein) in the rat was only present in a subset of retinal ganglion cells and in a few displaced amacrine or displaced ganglion cells; this finding agrees with the proposed localization in the inner retina of a specific "circadian" photoreceptor (Freedman et al., 1999; von Schantz et al., 2000). The expression of melanopsin in PACAP-containing retinal ganglion cells was demonstrated by a combination of in situ hybridization histochemistry/immunohistochemistry and by double immunohistochemistry. The number of retinal ganglion cells constituting the RHT is much higher in rats (Moore et al., 1995; Hannibal et al., 2001a) than in mice (Provencio et al., 1998a); however, of greater interest is the demonstration that the density of SCN-projecting cells was four- to fivefold higher in the superior than in the inferior retina. At present we have no explanation for this uneven distribution, but dopamine, which is a circadian transmitter of the retina, is located by a group of amacrine and displaced amacrine cells that also show a superiorinferior difference in density in the retina (Versaux-Botteri et al., 1986). Whether there is any relationship between these amacrine cells and the melanopsin/PACAP-containing cells remains to be investigated.

\section{Action spectra analysis of possible circadian photopigments}

Using action spectrum analysis for light entrainment of locomotor activity in mammals, it has been reported that the light-sensitive material responsible for circadian photoentrainment could be an opsin-based photopigment with an absorption peak of $\sim 500 \mathrm{~nm}$ (Takahashi et al., 1984; Provencio and Foster, 1995). However, in a recent study in humans, a photopigment with an absorption maximum close to $480 \mathrm{~nm}$ seemed to be involved in light-induced suppression of melatonin at night (Brainard et al., 2001). In blind $\mathrm{rd} / \mathrm{rd} / \mathrm{cl}$ mice that are able to entrain to a light/dark cycle, a photopigment with an absorption peak of $480 \mathrm{~nm}$ has been shown to mediate the pupillary light reflex (Lucas et al., 2001). A possible explanation for the observation described above could be the existence of at least two photopigments, one mediating pupillary reflex and melatonin suppression and one that is responsible for light entrainment of locomotor activity. To further clarify the role of melanopsin in circadian photoentrainment, the absorption peak needs to be determined. In contrast to melanopsin, the vitamin $\mathrm{B}_{2}$-based $C R Y 1$ and $C R Y 2$, which are present in a large number of retinal ganglion cells and in unidentified cells of the inner nuclear cell layer (Miyamoto and Sancar, 1998; Sancar, 2000), have absorption maxima close to $420 \mathrm{~nm}$ (Miyamoto and Sancar, 1998), making them less likely as circadian photoreceptors. This notion is supported by studies in $m C R Y$-deficient mice $\left(m C R Y 1^{-1-} ; m C R Y 2^{-1-}\right)$ demonstrating that although the $m C R Y$ s are important components of the molecular clock in the $\mathrm{SCN}$, they are not essential for transmitting light information to 

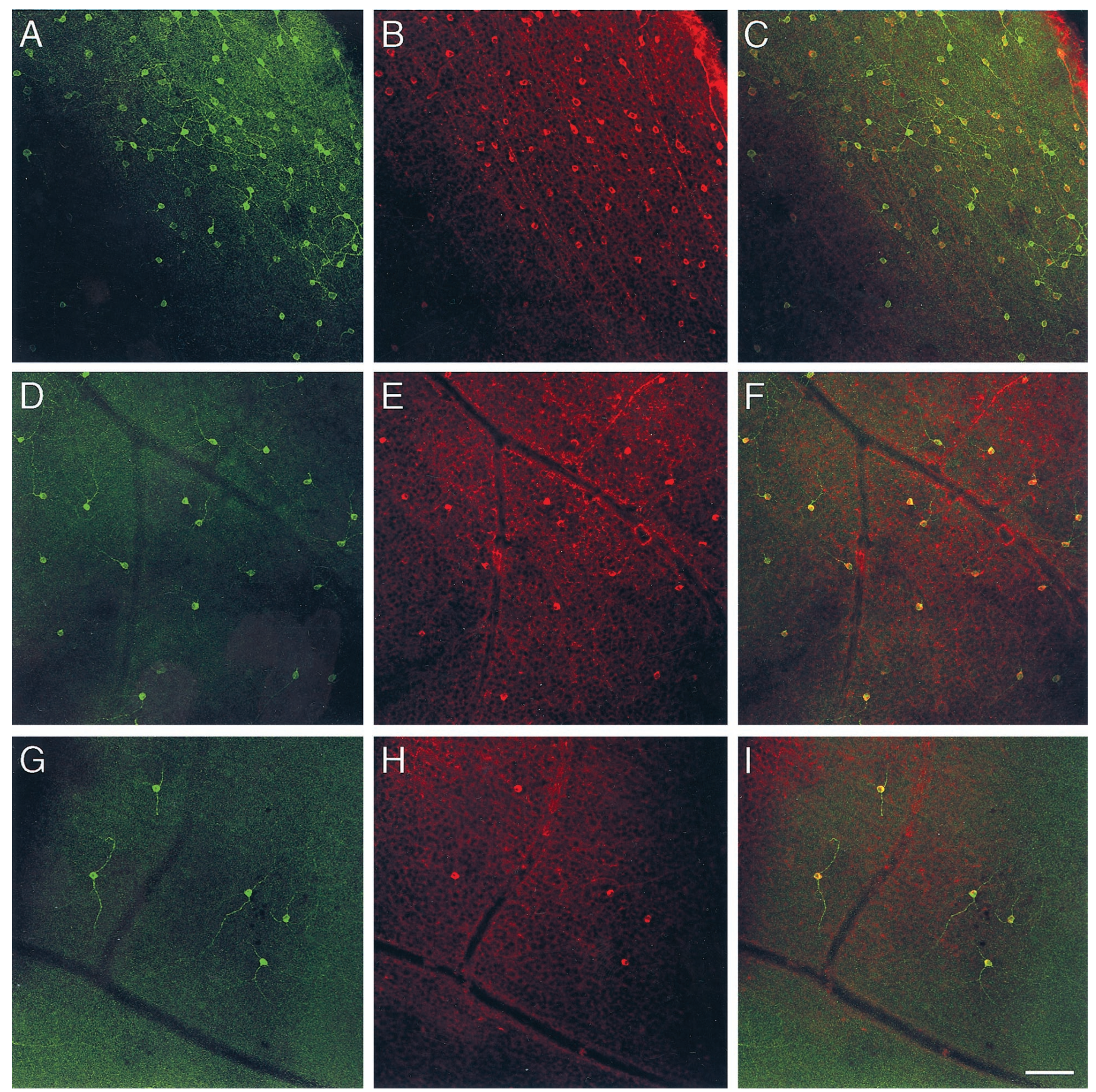

Figure 3. Melanopsin is exclusively located in PACAP-containing retinal ganglion cells. Confocal laser-scanning photomicrographs show three randomly selected parts of the retina double-immunostained for melanopsin $(A, D, G)$, PACAP $(B, E, H)$, and melanopsin/PACAP $(C, F, I)$. Scale bar, $100 \mu \mathrm{m}$

the SCN (Vitaterna et al., 1999). However, a role for the $C R Y$ s in light perception to the clock has been suggested recently. Triplemutant mice lacking both CRYs, rods, and cones $\left(\mathrm{rd}^{-} / \mathrm{rd}^{-}\right.$, $m C R Y 1^{-/-}, m C R Y 2^{-/-}$) were found to have lost the ability to adjust their behavioral rhythm to a $12 \mathrm{hr}$ light/dark cycle, in contrast to their littermate controls $\left(\mathrm{rd} / \mathrm{rd}^{-1-}, \mathrm{mCRY1^{-1- }}\right.$, and $m C R Y 2^{-1-}$ mutant mice (Selby et al., 2000). Whether the CRYs are directly photosensitive or whether they participate in a signaling pathway downstream to another photoreceptor like melanopsin is an open question.
Light activation of the retinal ganglion cells of the RHT The physiological properties of retinal ganglion cells of the RHT in response to light stimulation have been studied using extracellular recordings $(\mathrm{Pu}, 2000)$. Morphologically, cat retinal ganglion cells characterized as non- $\alpha$, non- $\beta$ cells $(\mathrm{Pu}, 1999)$ resemble the melanopsin/PACAP-containing retinal ganglion cells of the rat in terms of their size and number of dendritic processes (Hannibal et al., 1997, 2000, 2001a). The recordings are characterized by a sustained "on" response to light lasting as long as light is turned on and peaking at $500 \mathrm{~nm}(\mathrm{Pu}, 2000)$. We have shown recently 

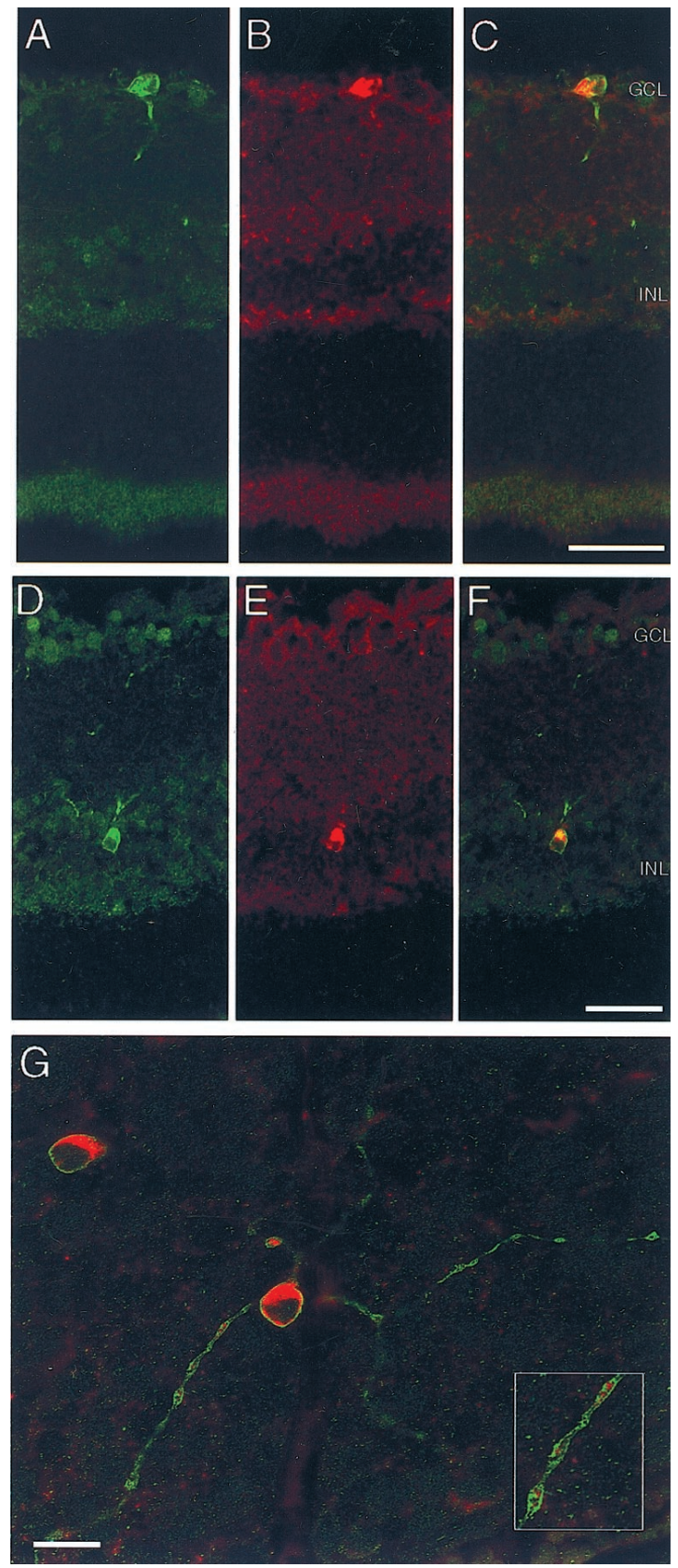

Figure 4. Melanopsin is present in PACAP-immunoreactive retinal ganglion cells and a few displaced ganglion/amacrine cells. Confocal photomicrographs of cross sections of rat retinas showing melanopsin $(A, D)$, $\operatorname{PACAP}(B, E)$, and melanopsin/PACAP $(C, F)$ in a retinal ganglion cell $(A-C)$ and in a single displaced retinal ganglion/amacrine cell. $G$, Confocal laser scanning photomicrograph showing double-immunostaining of melanopsin (green) and PACAP (red) in the same ganglion cells of whole-mount retinas. Note the punctate melanopsin immunoreactivity on the surface of the cell body and the processes. The inset shows high magnification of a melanopsin/PACAP-containing dendrite. GCL, Ganglion cell layer. Scale bars: $A-F, 50 \mu \mathrm{m} ; G, 20 \mu \mathrm{m}$.

that c-fos expression is induced by white light in the PACAPcontaining retinal ganglion cells and that Fos immunoreactivity is sustained only in the PACAP-containing retinal ganglion cells as long as light is turned on (Hannibal et al., 2001a). The presence of melanopsin on the PACAP-containing retinal ganglion cells suggests that the light-on response is attributable to activation of the melanopsin photopigment, possibly via a signaling pathway coupled to G-protein, and is regulated by kinases (Provencio et al., 1998b).

\section{Is PACAP an intraretinal transmitter?}

In addition to innervation of the SCN, PACAP-immunoreactive processes branch to the inner plexiform layer and INL (Hannibal et al., 2000). Furthermore, the PACAP-specific $P A C 1$ receptor is expressed in the INL of the rat retina (Seki et al., 1997). Thus, it is possible that light information received by the PACAPcontaining retinal ganglion cells could be transmitted to other retinal cells, and it is tempting speculate that the peptide may participate in the entrainment of the "retinal circadian clock" expressing many of the recently identified clock genes (King and Takahashi, 2000). In contrast, the melanopsin/PACAPcontaining cells may receive inputs from other retinal neurons.

In conclusion, our data, in conjunction with published action spectra analyses and work in retinally degenerated $(\mathrm{rd} / \mathrm{rd} / \mathrm{cl}) \mathrm{mu}$ tant mice, suggest that melanopsin is a circadian photoreceptor located in PACAP-containing retinal ganglion cells projecting to the biological clock.

\section{REFERENCES}

Berson DM, Dunn EA, Takao M (2001) Phototransduction by ganglion cells innervating the circadian pacemaker. Invest Ophthalmol Vis Sci 42:S113.

Brainard GC, Hanifin JP, Greeson JM, Byrne B, Glickman G, Gerner E, Rollag MD (2001) Action spectrum for melatonin regulation in humans: evidence for a novel circadian photoreceptor. J Neurosci 21:6405-6412.

Chen D, Buchanan GF, Ding JM, Hannibal J, Gillette MU (1999) PACAP: a pivotal modulator of glutamatergic regulation of the suprachiasmatic circadian clock. Proc Natl Acad Sci USA 96:13409-13414.

Czeisler CA, Shanahan TL, Klerman EB, Martens H, Brotman DJ, Emens JS, Klein T, Rizzo JF (1995) Suppression of melatonin secretion in some blind patients by exposure to bright light. N Engl J Med 332:6-11.

Ding JM, Chen D, Weber ET, Faiman LE, Rea MA, Gillette MU (1994) Resetting the biological clock: mediation of nocturnal circadian shifts by glutamate and NO. Science 266:1713-1717.

Fahrenkrug J, Hannibal J (1998) PACAP immunoreactivity in capsaicinsensitive nerve fibres supplying the rat urinary tract. Neuroscience 83:1261-1272.

Foster RG, Provencio I, Hudson D, Fiske S, De Grip W, Menaker M (1991) Circadian photoreception in the retinally degenerate mouse $(r d / r d)$. J Comp Physiol [A] 169:39-50.

Freedman MS, Lucas RJ, Soni B, von Schantz M, Muñoz M, David-Gray Z, Foster RG (1999) Regulation of mammalian circadian behavior by non-rod, non-cone, ocular photoreceptors. Science 284:502-504.

Hannibal J, Mikkelsen JD, Clausen H, Holst JJ, Wulff BS, Fahrenkrug J (1995) Gene expression of pituitary adenylate cyclase activating polypeptide (PACAP) in the rat hypothalamus. Regul Pept 55:133-148.

Hannibal J, Ding JM, Chen D, Gillette MU, Fahrenkrug J, Larsen PJ Mikkelsen JD (1997) Pituitary adenylate cyclase activating peptide (PACAP) in the retinohypothalamic tract. A daytime regulator of the biological clock. J Neurosci 17:2637-2644.

Hannibal J, Jessop D, Harbuz MS, Fahrenkrug J, Larsen PJ (1999) PACAP gene expression in neurons of the rat hypothalamo-pituitaryadrenocortical (HPA)-axis is induced by endotoxin and interleukin-1b. Neuroendocrinology 70:73-82.

Hannibal J, Moller M, Ottersen OP, Fahrenkrug J (2000) PACAP and glutamate are co-stored in the retinohypothalamic tract. J Comp Neurol 418:147-155.

Hannibal J, Vrang N, Card JP, Fahrenkrug J (2001a) Light-dependent induction of c-Fos during subjective day and night in PACAP containing retinal ganglion cells of the retino-hypothalamic tract. J Biol Rhythms 16:457-470.

Hannibal J, Brabet P, Jamen F, Nielsen HS, Journot L, Fahrenkrug J (2001b) Dissociation between light-induced phase shift of the circadian rhythm and clock gene expression in mice lacking the PACAP type 1 receptor (PAC1). J Neurosci 21:4883-4890.

Harrington ME, Hoque S, Hall A, Golombek D, Biello S (1999) Pituitary adenylate cyclase activating peptide phase shifts circadian rhythms in a manner similar to light. J Neurosci 19:6637-6642.

Hindersson P, Knudsen JD, Axelsen NH (1987) Cloning and expression of Treponema pallidum common antigen (Tp4): an antigen common to a wide range of bacteria. J Gen Microbiol 133:587-596. 
Johnson RF, Moore RY, Morin LP (1998) Loss of entrainment and anatomical plasticity after lesions of the hamster retinohypothalamic tract. Brain Res 460:297-313.

King DP, Takahashi JS (2000) Molecular genetics of circadian rhythms in mammals. Annu Rev Neurosci 23:713-742.

Klein DC, Moore RY, Reppert SM (1991) Suprachiasmatic nucleus: the mind's clock. New York: Oxford UP.

Kopp M, Schomerus C, Dehghani F, Korf HW, Meissl H (1999) Pituitary adenylate cyclase activating polypeptide and melatonin in the suprachiasmatic nucleus: effects on the calcium signal transduction cascade. J Neurosci 19:20619-219.

Levine JD, Weiss ML, Rosenwasser AM, Miselis RR (1991) Retinohypothalamic tract in the female albino rat: a study using horseradish peroxidase conjugated to cholera toxin. J Comp Neurol 306:344-360.

Lucas RJ, Foster RG (1999) Photoentrainment in mammals: a role for cryptochrome? J Biol Rhythms 14:4-10.

Lucas RJ, Freedman MS, Munoz M, Garcia-Fernandez JM, Foster RG (1999) Regulation of the mammalian pineal by non-rod, non-cone, ocular photoreceptors. Science 284:505-507.

Lucas RJ, Douglas RH, Foster RG (2001) Characterization of an ocular photopigment capable of driving pupillary constriction in mice. Nat Neurosci 4:621-626.

Mintz EM, Marvel CL, Gillespie CF, Price KM, Albers HE (1999) Activation of NMDA receptors in the suprachiasmatic nucleus produces light-like phase shifts of the circadian clock in vivo. J Neurosci 19:5124-5130.

Miyamoto Y, Sancar A (1998) Vitamin B2-based blue-light photoreceptors in the retinohypothalamic tract as the photoactive pigments for setting the circadian clock in mammals. Proc Natl Acad Sci USA 95:6097-6102.

Miyamoto Y, Sancar A (1999) Circadian regulation of cryptochrome genes in the mouse. Brain Res Mol Brain Res 71:238-243.

Moore RY, Lenn NJ (1972) A retinohypothalamic projection in the rat. J Comp Neurol 146:1-14.

Moore RY, Speh JC, Card JP (1995) The retinohypothalamic tract originates from a distinct subset of retinal ganglion cells. J Comp Neurol 352:351-366.

Nelson RJ, Zucker I (1981) Absence of extraocular photoreception in diurnal and nocturnal rodents exposed to direct sunlight. Comp Biochem Physiol A Physiol 69:145-148.

Nielsen HS, Hannibal J, Knudsen SM, Fahrenkrug J (2001) Pituitary adenylate cyclase activating polypeptide induces period 1 and period 2 gene expression in the rat suprachiasmatic nucleus (SCN) during late night. Neuroscience 103:433-441.

Provencio I, Foster RG (1995) Circadian rhythms in mice can be regulated by photoreceptors with cone-like characteristics. Brain Res 694:183-190.

Provencio I, Cooper HM, Foster RG (1998a) Retinal projections in mice with inherited retinal degeneration: implications for circadian photoentrainment. J Comp Neurol 395:417-439.

Provencio I, Jiang G, De Grip WJ, Hayes WP, Rollag MD (1998b) Melanopsin: an opsin in melanophores, brain, and eye. Proc Natl Acad Sci USA 95:340-345.

Provencio I, Rodriguez IR, Jiang G, Hayes WP, Moreira EF, Rollag MD (2000) A novel human opsin in the inner retina. J Neurosci 20:600-605.

Pu M (1999) Dendritic morphology of cat retinal ganglion cells projecting to suprachiasmatic nucleus. J Comp Neurol 414:267-274.

$\mathrm{Pu}$ M (2000) Physiological response properties of cat retinal ganglion cells projecting to suprachiasmatic nucleus. J Biol Rhythms 15:31-36.

Sancar A (2000) Cryptochrome: the second photoactive pigment in the eye and its role in circadian photoreception. Annu Rev Biochem 69:31-67.

Seki T, Shioda S, Ogino D, Nakai Y, Arimura A, Koide R (1997) Distribution and ultrastructural localization of a receptor for pituitary adenylate cyclase activating polypeptide and its mRNA in the rat retina. Neurosci Lett 238:127-130.

Selby CP, Thompson C, Schmitz TM, Van Gelder RN, Sancar A (2000) Functional redundancy of cryptochromes and classical photoreceptors for nonvisual ocular photoreception in mice. Proc Natl Acad Sci USA 97:14697-14702.

Takahashi JS, DeCoursey PJ, Bauman L, Menaker M (1984) Spectral sensitivity of a novel photoreceptive system mediating entrainment of mammalian circadian rhythms. Nature 308:186-188.

van der Horst GT, Muijtjens M, Kobayashi K, Takano R, Kanno S, Takao M, de Wit J, Verkerk A, Eker AP, van Leenen D, Buijs R, Bootsma D, Hoeijmakers JH, Yasui A (1999) Mammalian Cry1 and Cry2 are essential for maintenance of circadian rhythms. Nature 398:627-630.

Versaux-Botteri C, Martin-Martinelli E, Nguyen-Legros J, Geffard M, Vigny A, Denoroy L (1986) Regional specialization of the rat retina: catecholamine-containing amacrine cell characterization and distribution. J Comp Neurol 243:422-433.

Vitaterna MH, Selby CP, Todo T, Niwa H, Thompson C, Fruechte EM, Hitomi K, Thresher RJ, Ishikawa T, Miyazaki J, Takahashi JS, Sancar A. (1999) Differential regulation of mammalian period genes and circadian rhythmicity by cryptochromes 1 and 2. Proc Natl Acad Sci USA 96:12114-12119.

von Gall C, Duffield GE, Hastings MH, Kopp M, Dehghani F, Korf HW, Stehle JH (1998) CREB in the mouse SCN: a molecular interface coding the phase-adjusting stimuli light, glutamate, PACAP, and melatonin for clockwork access. J Neurosci 18:10389-10397.

von Schantz M, Provencio I, Foster RG (2000) Recent developments in circadian photoreception: more than meets the eye. Invest Ophthalmol Vis Sci 41:1605-1607. 